\title{
Systematic Review of Late Pleistocene Turtles (Reptilia: Chelonii) from the Ryukyu Archipelago, Japan, with Special Reference to Paleogeographical Implications ${ }^{1}$
}

\author{
Akio Takahasbi, ${ }^{2}$ Hiroyuki Otsuka, ${ }^{3}$ and Hidetoshi Ota ${ }^{4,5}$
}

\begin{abstract}
The Quaternary terrestrial turtle fauna of the Ryukyu Archipelago was reviewed on the basis of recently excavated fossils, as well as literature information. As a result, five extinct species (four geoemydids [Cuora sp., Geoemyda amamiensis, Mauremys sp., and another species with undetermined generic and specific status] and one testudinid [Manouria oyamai]) were recognized from Late Pleistocene cave and fissure deposits. Two of the three turtles currently occurring in this archipelago (C. flavomarginata and G. japonica) were also recognized from comparable deposits on islands, including those where they do not occur at present. These records indicate that the terrestrial turtles of the Ryukyus were much more diverse during the Late Pleistocene than at present, and that extinction has occurred during the last few tens of thousands of years not only for those five fossil species but also for some island populations of the extant species. Distributions of three of the extinct species (G. amamiensis, Cuora sp., and the geoemydid [genus and species undetermined]), confined to the central Ryukyus, are concordant with the currently prevailing hypothesis of Ryukyu paleogeography, which assumes a relatively long isolation of this region and much more recent insularization of the southern Ryukyus. In contrast, distributions of the remaining two extinct species (Man. oyamai and Mau. sp.) must be explained by some ad hoc scenario or, otherwise, drastic modification of the current hypothesis.
\end{abstract}

The Ryukyu Archipelago is a chain of continental islands located between the main

\footnotetext{
${ }^{1}$ This study was supported by a grant from the 21 st Century COE Program entitled "The Comprehensive Analyses on Biodiversity in Coral Reef and Island Ecosystems in Asian and Pacific Regions" to the University of the Ryukyus, and also by Grants-in-Aid for Basic Researches (C-16540427 to H. Otsuka, and C-18570090 to H. Ota), all from the Japan Ministry of Education, Culture, Sports, Science, and Technology (Monbu-kagakusho). Manuscript accepted 24 August 2007.

2 The 21 st Century COE, University of the Ryukyus, Nishihara, Okinawa 903-0213, Japan.

${ }^{3}$ The Kagoshima University Museum, Kagoshima 890-0065, Japan.

${ }^{4}$ Tropical Biosphere Research Center, University of the Ryukyus, Nishihara, Okinawa 903-0213, Japan. .ac.jp).

${ }^{5}$ Corresponding author (e-mail: ota@sci.u-ryukyu
}

Pacific Science (2008), vol. 62, no. 3:395-402

(C) 2008 by University of Hawai'i Press

All rights reserved islands of Japan and Taiwan (Figure 1). Initially land areas corresponding to this archipelago emerged as an eastern margin of the Eurasian continent in early Tertiary. Since the Late Miocene, the Ryukyu Archipelago has gradually been isolated from the latter through an extension of the Okinawa Trough (e.g., Kizaki and Oshiro 1977, Ujiié 1990). Based on current faunal characteristics and geographic features, the archipelago is usually divided into three regions: (1) northern Ryukyus, consisting of the Osumi Group and Tokara Islands north of the Tokara Tectonic Strait (henceforth referred to as the northern Tokara Islands) that are characterized by numerical dominance of species common to the main islands of Japan; (2) central Ryukyus, consisting of the Tokara Islands south of the strait (the southern Tokara Islands), the Amami Group, and the Okinawa Group that are characterized by high ratios of species endemic to this region; and (3) southern Ryukyus, consisting of the Miyako Group and 


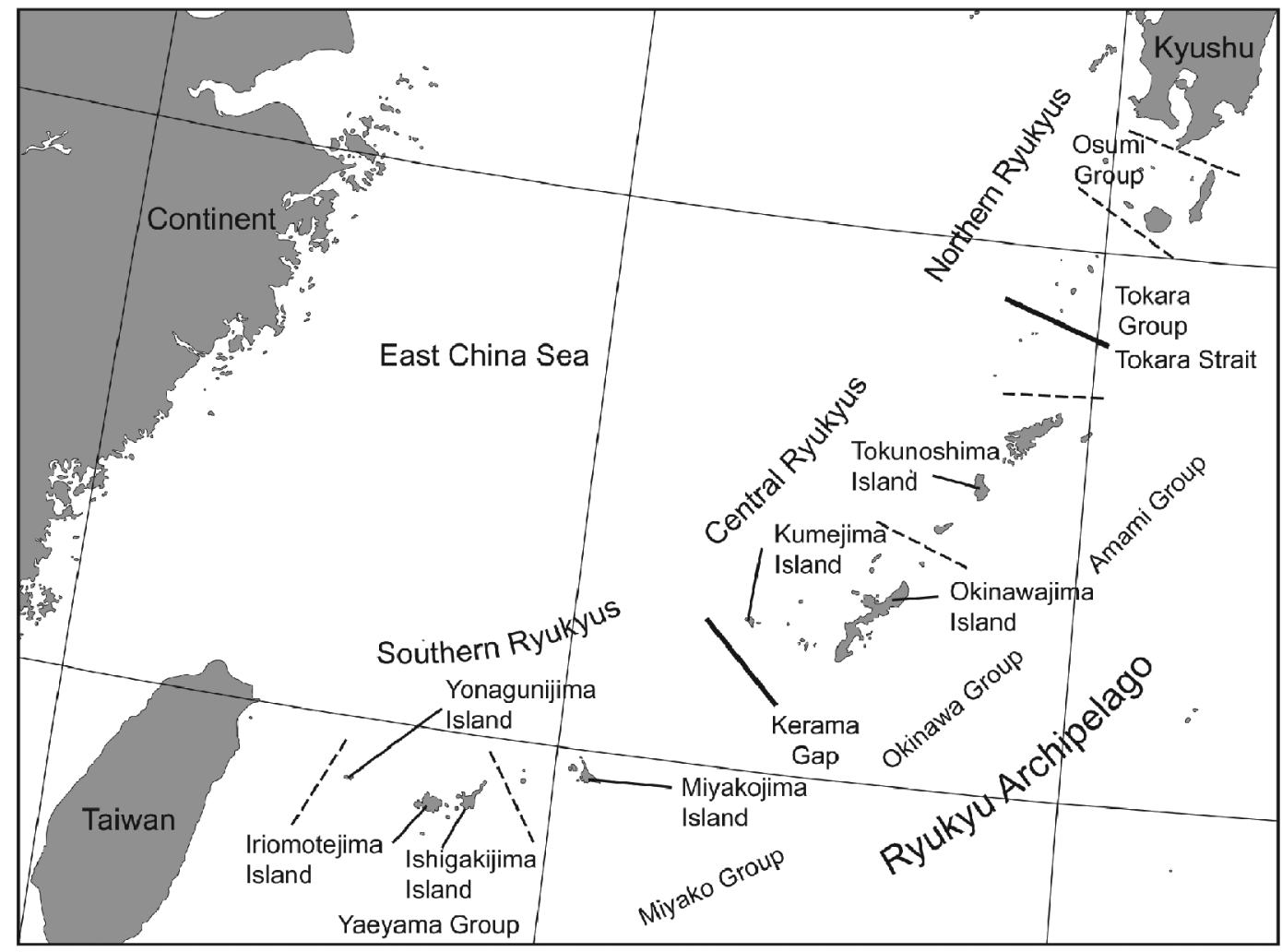

Figure 1. Map of the Ryukyu Archipelago showing geographic locations of islands, island groups, and straits referred to in text.

the Yaeyama Group that are characterized by high frequencies of species common to Taiwan but with occasional subspeciation (Ota 1998, 2000). Isolation of the central Ryukyus from surrounding landmasses by the Tokara Tectonic Strait in the northeast and the Kerama Gap in the southwest is generally considered to have begun some time between the Late Miocene and the Late Pliocene (Hikida and Ota 1997, Ota 1998). In contrast, islands of the northern and southern Ryukyus are considered to have been connected by landbridges to the main islands of Japan and Taiwan, respectively, or had not yet been exposed above the sea until the Middle Pleistocene or even later (e.g., Hikida and Ota 1997, Ota 1998, Kimura 2002).

Recent biochemical and molecular phylo- geographical studies of extant vertebrates give results that are largely concordant with these paleogeographical hypotheses (e.g., Hayashi and Matsui 1988, Toda et al. 1999, Tu et al. 2000, Ota et al. 2002; but see Kato et al. [1994] and Matsui et al. [2005a,b] for examples of different hypotheses). Reconstructing the paleobiogeography from extant populations can prove difficult because of confounding variables, such as localized extinctions and genetic drift. Therefore, hypotheses of Ryukyu paleobiogeography require testing from independent lines of evidence.

Fossils provide an opportunity to test paleobiogeographical hypotheses based on data from extant populations (Lieberman 2003). Fortunately, most islands of the Ryukyus are 
more or less covered by Pleistocene coral reef complex deposits (collectively referred to as the Ryukyu Group or the so-called "Ryukyu Limestone"). The Ryukyu Group preserves abundant Late Pleistocene animal fossils in fissures and cave deposits. The taxonomic status and phylogenetic affinities of most Ryukyu fossils remain uncertain, chiefly due to the paucity of appropriate comparisons (e.g., see Ota [2003]). This has hindered the use of fossil evidence to inform Ryukyu paleobiogeography.

Turtles (Reptilia: Chelonii) are among the most commonly fossilized organisms. Turtles are useful paleobiogeographical indicators because their skeletons include shell elements that are not only durable and amenable to fossilization but also allow strong inferences about their phylogenetic relationships. By comparing fossils of different ages and from different localities, detailed paleobiogeographic patterns can be developed. Keeping this advantage in mind, we have been investigating taxonomic status and phylogenetic affinities of fossil terrestrial turtles discovered from the Upper Pleistocene in the Ryukyu Archipelago by making detailed comparisons on the basis of broad material (e.g., Takahashi et al. 2003, 2007). Here, we briefly review these turtles and discuss their paleobiogeographic implications.

\section{MATERIALS AND METHODS}

Data for turtle fossils from fissure fillings and cave deposits on several Ryukyu islands were taken from both recent publications and unpublished sources. The radiocarbon method dated these deposits as a few tens of thousands of years before the present (i.e., the Late Pleistocene [Takahashi et al. 2003]).

Shell terminology follows Zangerl (1969). For specimens directly examined by us, measurements were taken to the nearest $0.1 \mathrm{~mm}$ using digital slide calipers. Catalog numbers of specimens deposited in the geological collections of Faculty of Science, Kagoshima University, and of the University Museum, University of the Ryukyus (Fujukan), are preceded by ESK and RUMF, respectively.
RESULTS

\section{Taxonomic Accounts}

Family Testudinidae

Manouria oyamai. This is a relatively large extinct testudinid, found from Tokunoshima Island of the Amami Group, Iejima and Okinawajima Islands of the Okinawa Group, and Miyakojima Island of the Miyako Group (Takahashi et al. 2003). Also, a partially broken left femur bone $(62.5 \mathrm{~mm}$ in maximum length and $14.4 \mathrm{~mm}$ in minimum width), recently excavated by us from Agarizaki on Yonagunijima Island of the Yaeyama Group (ESK-6240 [Figure $2 A-B$ ]), seems to be most appropriately identified to $M$. oyamai, judging from its large size and markedly tapering femoral shaft.

\section{Family Geoemydidae}

Geoemyda japonica. This species is an extant central Ryukyu endemic currently confined to Kumejima, Tokashikijima, and Okinawajima Islands of the Okinawa Group (Yasukawa et al. 1992). Fossils referred to this species have been recorded from Iejima Island of the Okinawa Group where this species does not occur at present (Hasegawa et al. 1978, Toyama 1997, Toyama and Hirayama 2001), as well as from Kumejima (Takahashi et al. 2003) and Okinawajima Islands (e.g., Oshiro 1994, Nohara and Irei 2002). Of these, two of the four specimens referred to as G. japonica in Hasegawa et al. (1978: specimen nos. 18 and 20 in plate 12) are obviously different from this species because of the presence of a very small posterior plastral notch and unserrated anterolateral or posterolateral margin of the carapace (versus the posterior plastral notch being wide and shallow, and both the anterolateral and posterolateral portions of the carapace distinctly serrated in G. japonica [see Yasukawa et al. (1992)]). Currently we tentatively attribute these two specimens to Cuora sp. (see discussion under Cuora sp.).

Geoemyda amamiensis. This extinct geoemydid, recently discovered from Tokunoshima Island of the Amami Group, is obviously closest to G. japonica. Nevertheless, detailed 


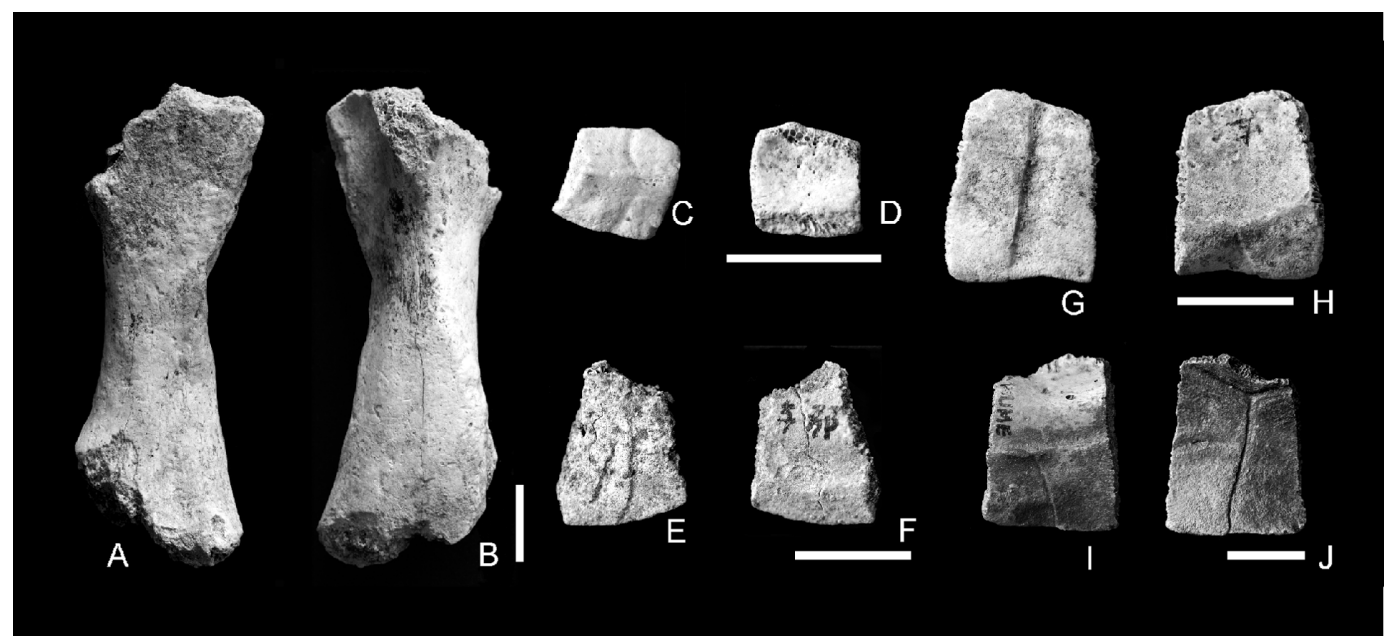

Figure 2. Terrestrial turtle fossils recently excavated from the Late Pleistocene deposits of the Ryukyu Archipelago. $A-B$, left femur of Manouria oyamai from Yonagunijima Island (ESK-6240) in ventral $(A)$ and dorsal views $(B)$. $C-D$, right sixth peripheral of Cuora flavomarginata from Ishigakijima Island (RUMF-GF-5015) in dorsal $(C)$ and ventral views $(D)$. E-H, left first peripheral (ESK-6242) and putative left tenth peripheral (ESK-6241) of C. flavomarginata from Yonagunijima Island in dorsal $(E$ and $G)$ and ventral views $(F$ and $H) . I-7$, left ninth peripheral (RUMF-GF$5016)$ of the geoemydid turtle from Kumejima Island (genus and species undetermined) in ventral $(I)$ and dorsal views (7). Scale bars $=10 \mathrm{~mm}$.

morphological investigations revealed distinct differentiation of this Tokunoshima endemic from that species (Takahashi et al. 2007).

Cuora flavomarginata. We tentatively identify fossils recently discovered from Ibaruma (eight specimens) on Ishigakijima Island and Agarizaki (two specimens) on Yonagunijima Island, Yaeyama Group, as this extant species, although it does not currently occur on the latter island (Yasukawa and Ota 1999). The fossils from Ibaruma seem to represent a single individual, because they were found together, and all are equally small, the juvenile size for this species. Of these, RUMF-GF5015 (the right sixth peripheral: $7.5 \mathrm{~mm}$ long and $7.2 \mathrm{~mm}$ wide) has the wide scar for ligamentous connection to the plastron ventromedially, a feature characteristic of the genera Cuora sensu Honda et al. (2002) and Pyxidea or of the genus Cuora sensu Spinks et al. (2004) (Figure $2 C$ and $D$ ) (Yasukawa et al. 2001, Joyce and Bell 2004; A.T., unpubl. data). Two other specimens, ESK-6242 (the left first peripheral: $14.3 \mathrm{~mm}$ long and 11.2 $\mathrm{mm}$ wide) and ESK-6241 (most likely the left tenth peripheral: $16.5 \mathrm{~mm}$ long and 13.3 $\mathrm{mm}$ wide), are also very similar to those of extant C. flavomarginata in having a series of long marginal scutes reaching the costaloperipheral suture on the dorsal side (Figure $2 E-H)$.

Cuora sp. Several geoemydid fossils, excavated from Iejima, Kumejima, and Okinawajima Islands of the Okinawa Group, are referred to as representing an extinct species of the genus Cuora (Otsuka and Takahashi 2000, Takahashi et al. 2003; A.T., pers. obs. [see discussion under Geoemyda japonica]). Of these, materials from Okinawajima Island differ obviously from $C$. flavomarginata by the presence of an anal notch and the shape of the iliac blade (Takahashi et al. 2004). In addition, our recent surveys yielded several turtle fossils from Tokunoshima Island of the Amami Group that are seemingly conspecific or very closely related to this fossil Cuora from the Okinawa Group (A.T., T. Kato, and H. Ota, unpubl. data).

Mauremys sp. Hasegawa et al. (1973) reported two pieces of turtle fossils from Miya- 
kojima Island and tentatively referred them to Mauremys mutica, a species whose extant natural populations in the Ryukyus are confined to Ishigakijima, Iriomotejima, and Yonagunijima Islands of the Yaeyama Group; they are regarded as an endemic subspecies, $M . m$. kami (Yasukawa et al. 1996). Recently, we examined morphological features of these fossils in detail together with another fossil found from the same site. Comparisons with most extant and extinct geoemydids strongly suggest that these Miyakojima fossils represent an undescribed Mauremys species distinct from M. mutica and endemic to Miyakojima Island (A.T., H. Otsuka, and H. Ota, in prep.).

?Mauremys mutica. Hasegawa and Nohara (1978) tentatively referred to a turtle fossil from Ishisukuyama on Ishigakijima Island as M. mutica. However, this fossil is no more than a proximal portion of the humerus. Moreover, those authors did not provide justification for their identification. Therefore, taxonomic allocation of this fossil and occurrence of M. mutica in the Yaeyama Group in the Late Pleistocene definitely need further verification.

Geoemydidae, genus and species undetermined. Several fragments of turtle fossils have also been collected from Ohara and $\mathrm{Na}-$ kachi in the eastern part of Kumejima Island (H. Otsuka and A.T., unpubl. data). Some of these remain unidentified. For example, RUMF-GF-5016 (the left ninth peripheral: $23.3 \mathrm{~mm}$ long and $18.4 \mathrm{~mm}$ wide) is obviously distinct from Cuora spp. (including both Cuora sp. mentioned earlier and C. flavomarginata) by the presence of a long marginal scute on the ventral surface, from G. japonica by the absence of strong marginal serration, and from $M$. mutica by the presence of a long marginal scute on the dorsal surface. However, further studies on the basis of additional materials are needed to determine its taxonomic status.

\section{DISCUSSION}

As shown here, a total of five extinct species and at least two of the three extant species of terrestrial turtles have been found from the Late Pleistocene deposits of the Ryukyus (Table 1). Fossils that can be identified to $M$. mutica with certainty have not yet been discovered from this archipelago, although fossils of the other extant southern Ryukyu geoemydid, C. flavomarginata, are found from two localities (see Results). This may reflect a very recent origin of the southern Ryukyu M. mutica populations, even though they exhibit slight morphological differentiation from conspecific populations of Taiwan and eastern continental China, for which the southern Ryukyu populations are regarded as

TABLE 1

Distributions of Terretrial Turtles Known from Late Pleistocene Deposits of the Ryukyu Archipelago

\begin{tabular}{|c|c|c|c|c|c|c|c|}
\hline \multirow[b]{3}{*}{ Species } & \multicolumn{3}{|c|}{ Southern Ryukyus } & \multicolumn{4}{|c|}{ Central Ryukyus } \\
\hline & \multicolumn{2}{|c|}{ Yaeyama Group } & \multirow{2}{*}{$\frac{\text { Miyako Group }}{\text { Miyakojima }}$} & \multicolumn{3}{|c|}{ Okinawa Group } & \multirow{2}{*}{$\frac{\text { Amami Group }}{\text { Tokunoshima }}$} \\
\hline & Yonagunijima & Ishigakijima & & Kumejima & Okinawajima & Iejima & \\
\hline Manouria oyamai & + & & + & & + & + & + \\
\hline Cuora flavomarginata & + & + & & & & & \\
\hline Cuora sp. & & & & + & + & + & + \\
\hline Geoemyda japonica & & & & & + & + & \\
\hline Geoemyda amamiensis & & & & & & & + \\
\hline ?Mauremys mutica & & + & & & & & \\
\hline Mauremys sp. & & & + & & & & \\
\hline $\begin{array}{l}\text { Geoemydidae, gen. } \\
\text { and sp. undet. }\end{array}$ & & & & + & & + & \\
\hline
\end{tabular}


an endemic subspecies (M. m. kami [Yasukawa et al. 1996]). Further fossil surveys, as well as detailed molecular phylogeographical analyses of extant populations of M. mutica, are strongly advocated.

Of the other fossils identified to extant species, those of C. flavomarginata from Yonagunijima Island and G. japonica from Iejima Island indicate that geographic ranges of these species were broader during the Late Pleistocene. Fossils representing the five extinct turtles (Manouria oyamai, G. amamiensis, Cuora sp., Mauremys sp., and the unique geoemydid from Kumejima Island [see Results]) suggest that the terrestrial turtle fauna of the Ryukyus was once nearly three times as rich in species as currently and that the high species richness continued up to very end of the Pleistocene.

Discovery of G. amamiensis from Tokunoshima Island offers another case of substantial divergence in a single clade within the central Ryukyus (Takahashi et al. 2007). This is concordant with Ota's (1998) view that the primary vicariance within this region took place between this island and the Okinawa Group. On the other hand, occurrences of Mauremys sp. on Miyakojima Island and of M. oyamai on Tokunoshima, Iejima, Okinawajima, Miyakojima, and Yonagunijima Islands are obviously incongruent with the currently prevailing view of Ryukyu paleobiogeography: the former species challenges the view of recent (i.e., late Middle Pleistocene or even later) emergence and consistent subsequent isolation of Miyakojima Island (Kimura 1996, 2002), and the latter species casts substantial doubt on the validity of the Kerama Gap as a long-standing effective barrier against the dispersal of nonvolant terrestrial animals (Ota 1998, 2000). These two species seem to require ad hoc hypotheses to explain their historical biogeography, or otherwise a drastic modification of the currently prevailing hypothesis of Ryukyu paleobiogeography is needed.

The current results indicate that the majority of Late Pleistocene terrestrial turtles of the Ryukyu Archipelago have gone extinct during the latest Pleistocene-Holocene pe- riod, leaving only three species at most currently. Such abrupt extinction of those turtles is obviously a part of the massive extinction of terrestrial vertebrates of the Ryukyus during this period, which seems to have been caused by human activities, or prominent climate change, or both (e.g., Kuroda and Ozawa 1996, Takahashi et al. 2003).

The number of Late Pleistocene turtle taxa excavated from the Ryukyu Archipelago has been increasing consistently during the last few decades. Therefore, further fossil search efforts may allow for a better understanding of turtle evolution and biogeographical history in this archipelago.

\section{ACKNOWLEDGMENTS}

We thank R. Hirayama (Waseda University, Japan) and Y. Yasukawa (University of the Ryukyus, Japan) for many helpful comments and constructive criticism and two anonymous reviewers for improving an early version of the manuscript. We are also much indebted to T. Ikeda (Kagoshima University) and T. Kato (Kurashiki University of Science and the Arts) for helping us with field surveys and S. Arakaki for permitting us to excavate fossils in Sabichi-do, a limestone cave on Ishigakijima Island.

\section{Literature Cited}

Hasegawa, Y., and T. Nohara. 1978. Summary of the animal remains at Ishisukuyama, Ishigaki City. Pages 49-78 in Preliminary report of excavation of Ishisukuyama. Okinawa Prefectural Board of Education, Naha [in Japanese].

Hasegawa, Y., T. Nohara, H. Nokariya, and K. Ono. 1978. Animal remains from the Gohezu-do Cave. Pages 8-17 and plates 3-12 in Educational Committee of Ie Village, ed. A preliminary report from the 2nd survey of the Pleistocene deposits of Gohez Limestone Cave, Iejima Island, Okinawa, Japan. Board of Education, Ie Village, Okinawa [in Japanese].

Hasegawa, Y., H. Otsuka, and T. Nohara. 1973. Fossil vertebrates from Miyako 
Island. Mem. Natl. Sci. Mus. (Tokyo) 6:39-52, 2 pls. (in Japanese with English abstract).

Hayashi, T., and M. Matsui. 1988. Biochemical differentiation in Japanese newts, genus Cynops (Salamandridae). Zool. Sci. (Tokyo) 5:1121-1136.

Hikida, T., and H. Ota. 1997. Biogeography of reptiles in the subtropical East Asian islands. Pages 11-28 in K. Y. Lue and T.-H. Chen, eds. Proceedings of the symposium on the phylogeny, biogeography and conservation of fauna and flora of East Asian region. National Science Council, Taipei.

Honda, M., Y. Yasukawa, R. Hirayama, and H. Ota. 2002. Phylogenetic relationships of the Asian box turtles of the genus Cuora sensu lato (Reptilia: Bataguridae) inferred from mitochondrial DNA sequences. Zool. Sci. (Tokyo) 19:1305-1312.

Joyce, W. G., and C. J. Bell. 2004. A review of comparative morphology of extant testudinoid turtles (Reptilia: Testudines). Asiatic Herpetol. Res. 10:53-109.

Kato, J., H. Ota, and T. Hikida. 1994. Biochemical systematics of the latiscutatus species-group of the genus Eumeces (Scincidae: Reptilia) from East Asian islands. Biochem. Syst. Ecol. 22:491-500.

Kimura, M. 1996. Quaternary paleogeography of the Ryukyu arc. J. Geogr. (Chigaku-Zasshi) 105:259-285 [in Japanese with English abstract].

_ 2002. Establishment and paleogeography of the Ryukyu arc. Pages 19-54 in M. Kimura, ed. The formation of the Ryukyu arc and migration of biota. Okinawa Times, Naha [in Japanese].

Kizaki, K., and I. Oshiro. 1977. Paleogeography of the Ryukyu Islands. Kaiyou Mon. 9:38-45 [in Japanese].

Kuroda, T., and T. Ozawa. 1996. Paleoclimatic and vegetational changes during the Pleistocene and Holocene in the Ryukyu Islands inferred from pollen assemblages. J. Geogr. (Chigaku-Zasshi) 105:328-342 [in Japanese with English abstract].

Lieberman, B. S. 2003. Paleogeography: The relevance of fossils to biogeography. Ann. Rev. Ecol. Evol. Syst. 34:51-69.
Matsui, M., H. Ito, T. Shimada, H. Ota, S. K. Saidapur, W. Khonsue, T. Tanaka-Ueno, and G.-F. Wu. 2005a. Taxonomic relationships within the pan-Oriental narrowmouth toad Microbyla ornata as revealed by mtDNA analysis (Amphibia, Anura, Microhylidae). Zool. Sci. (Tokyo) 22:489-495.

Matsui, M., T. Shimada, H. Ota, and T. Tanaka-Ueno. 2005b. Multiple invasions of the Ryukyu Archipelago by Oriental frogs of the subgenus Odorrana with phylogenetic reassessment of the related subgenera of the genus Rana. Mol. Phylogenet. Evol. 37:733-742.

Nohara, T., and S. Irei. 2002. Animal remains of the Minatogawa fissure site. Pages 2987 in Educational Committee of Gushikami Village, ed. Minatogawa fissure site. Board of Education, Gushikami Village, Okinawa [in Japanese].

Oshiro, I. 1994. Terrestrial vertebrate fossils from the Futenma-gu site, Ginowan City, Okinawa, Japan. J. Geogr. (ChigakuZasshi) 103:49-63 [in Japanese with English abstract].

Ota, H. 1998. Geographic patterns of endemism and speciation in amphibians and reptiles of the Ryukyu Archipelago, Japan, with special reference to their paleogeographic implications. Res. Popul. Ecol. 40:189-204.

- 2000. The current geographic faunal pattern of reptiles and amphibians of the Ryukyu Archipelago and adjacent regions. Tropics 10:51-62.

- 2003. Toward a synthesis of paleontological and neontological information on the terrestrial vertebrates of the Ryukyu Archipelago. I. Systematic biogeographic review. J. Fossil Res. 36:43-59.

Ota, H., M. Honda, S.-L. Chen, T. Hikida, S. Panha, H.-S. Oh, and M. Matsui. 2002. Phylogenetic relationships, taxonomy, character evolution and biogeography of the lacertid lizards of the genus Takydromus (Reptilia: Squamata): A molecular perspective. Biol. J. Linn. Soc. 76:493-509.

Otsuka, H., and A. Takahashi. 2000. Pleistocene vertebrate faunas in the Ryukyu 
Islands: Their migration and extinction. Tropics 10:25-40.

Spinks, P. Q., H. B. Shaffer, J. B. Iverson, and W. P. McCord. 2004. Phylogenetic hypotheses for the turtle family Geoemydidae. Mol. Phylogenet. Evol. 32:164-182.

Takahashi, A., R. Hirayama, and H. Otsuka. 2003. A new species of the genus Manouria (Testudines: Testudinidae) from the Upper Pleistocene of the Ryukyu Islands, Japan. Paleontol. Res. 7:195-217.

Takahashi, A., T. Kato, and H. Ota. 2007. A new species of the genus Geoemyda (Chelonii: Geoemydidae) from the Upper Pleistocene of Tokunoshima Island of the central Ryukyus, Japan. Curr. Herpetol. 26:1-11.

Takahashi, A., H. Otsuka, and R. Hirayama. 2004. Fossil Asian box turtle, Cuora sp. from the latest Pleistocene of Okinawa Island, Japan. Page 25 in Program of the 153rd Regular Meeting of the Palaeontological Society of Japan [abstract only].

Toda, M., M. Nishida, M.-C. Tu, T. Hikida, and H. Ota. 1999. Genetic variation, phylogeny and biogeography of the pit vipers of the genus Trimeresurus sensu lato (Reptilia: Viperidae) in the subtropical East Asian islands. Pages 249-270 in H. Ota, ed. Tropical island herpetofauna: Origin, current diversity and conservation. Elsevier Science, Amsterdam.

Toyama, M. 1997. On Geoemyda japonica found from the Gushibaru shell midden. Pages 189-194 in Report of excavation of Gushibaru shell midden, Iejima Island. Okinawa Prefectural Board of Education, Naha [in Japanese].

Toyama, M., and R. Hirayama. 2001. On the turtle remains found from the Nagarabaru-higashi shell midden. Pages 47-49 in A. Shinzato, ed. Reports of the Laboratory for Archaeology, I, Nagarabaru-nishi shell midden, part 3. Laboratory of Archaeology, Faculty of Letters, Kumamoto University, Kumamoto [in Japanese].

Tu, M.-C., H.-Y. Wang, M.-P. Tsai, M. Toda, W.-J. Lee, F.-J. Zhang, and H. Ota. 2000. Phylogeny, taxonomy, and biogeography of the Oriental pitvipers of the genus Trimeresurus (Reptilia: Viperidae: Crotalinae): A molecular approach. Zool. Sci. (Tokyo) 17:1147-1157.

Ujiié, H. 1990. Geological history of the Ryukyu Island arc. Pages 251-255 in $\mathrm{H}$. Ujiié, ed. Nature of Okinawa: Geomorphology and geology. Hirugi-sha, Naha [in Japanese].

Yasukawa, Y., R. Hirayama, and T. Hikida. 2001. Phylogenetic relationships of geoemydine turtles (Reptilia: Bataguridae). Curr. Herpetol. 20:105-133.

Yasukawa, Y., and H. Ota. 1999. Geographic variation and biogeography of the geoemydine turtles (Testudines: Bataguridae) of the Ryukyu Archipelago, Japan. Pages 271-297 in H. Ota, ed. Tropical island herpetofauna: Origin, current diversity, and conservation. Elsevier Science, Amsterdam.

Yasukawa, Y., H. Ota, and T. Hikida. 1992. Taxonomic re-evaluation of the two subspecies of Geoemyda spengleri (Gmelin, 1789) (Reptilia: Emydidae). Jpn. J. Herpetol. 14:143-159.

Yasukawa, Y., H. Ota, and J. B. Iverson. 1996. Geographic variation and sexual size dimorphism in Mauremys mutica (Cantor, 1842) (Reptilia: Bataguridae), with description of a new subspecies from the southern Ryukyus, Japan. Zool. Sci. (Tokyo) 13:303-317.

Zangerl, R. 1969. The turtle shell. Pages 311-339 in C. Gans and T. Parsons, eds. Biology of the Reptilia. Vol. 1. Academic Press, New York. 